\title{
Review of: "The effects of environmental enrichment on hatchery-performance, smolt migration and capture rates in landlocked Atlantic salmon"
}

Feng You

Potential competing interests: The author(s) declared that no potential competing interests exist.

This published study presents environmental enrichment effects on pre- and post-release performance of landlocked Atlantic salmon in the Finnish Vuoksi water-course, which shows that enrichment of the rearing environment could improve the welfare and survival of the fish. The achievement could expand the views on strategies and alternatives for enriching the fish environment in aquaculture. Overall, the study was pretty well performed, and the used techniques and methods are solid. So, I think the study has higher valuable for researchers and other stakeholders, and is appropriate for the publication. The paper is generally well-written although there is little modified suggestion, such as the detailed data need to be shown in Abstract. Also, a few concerns shown as below are better to be included in the future study to give more support data for the conclusion.

1. The changes in responses to environmental enrichment depend on life-stage of the fish. Several studies showed contradictory and unexpected results may be due to the utilization of inadequate design for different life-stage. Thus, the authors need to provide the detail of the environmental enrichment, such as shelter amount (basal- area coverage) and substrate (pebbles, gravel, stones, etc.). Reporting detailed characteristics of items used as enrichment in study may help to reveal the different results vary among studies.

2. As the hydrodynamism have been shown to have both positive and negative effects on fish, usually with negative impacts at low and high levels and with least effects or positive impacts at intermediate levels, the detailed hydrodynamism for enriched and standard rearing tanks, including water flows and velocity, needs to be provided.

3. A previous study demonstrated that feed conversion rate can be improved in Atlantic salmon by inserting an array of enrichment in the rearing tank, but did not report significant differences in length and total weight gain. Thus, feed conversion rate of each group could be analyzed in the study. 